\title{
Aspectos Sociales de la Industrialización
}

\author{
por JosÉ MEJía VALERA
}

Uno de los principales problemas que afronta el desarrollo económico del Perú es, indudablemente, el estudio de los aspectos sociales de la industrialización y de la reforma agraria. A primera vista parecería que tales preocupaciones no tienen razón de ser ya que, podría pensarse, la implantación de industrias en gran escala no tendría mayores efectos que en el aspecto económico. Sin embargo, no es así.

Basta recordar las funestas consecuencias que en la vida social produjo la industrialización de Europa, como la despoblación del campo, la destrucción de la clase media tradicional, la crisis económica del artesanado, la aparición de un proletariado con tendencias al payperismo, etc. Si deseamos que algo semejante no ocurra en el Peru es preciso impulsar no sólo el desarrollo económico sobre la base del la industrialización sino, paralelamente, estudiar también cuales son las condiciones sociales favorables a dicho desarrollo.

La pregunta básica sería: ¿las actuales condiciones sociales son propicias o adversas a un proceso de industrialización en gran escala?

Para responder a ese interrogante se requiere iniciar una investigación social que abarque los distintos factores vinculados al problema central. Sería preciso averiguar, por ejemplo, cuales san las actitudes del empresariado nacional, si se inclinan a un desarrollo económico planificado, si existe espíritu de empresa, si su sistema de valores está en concordancia con el exigido por las nuevas condiciones económicas a crearse, etc. De igual modo, habría que averiguar cuales son los patrones de cultura de la mano de abra, su actitud frente a los empresarios, la medida en que aspiran cambiar el sistema social existente, etc. Puede darse el ca- 
so que un proceso de industrialización violento creare patrones de conducta individualista que sirviera de sustento a un sistema competitivo, el cual tendría que entrar, necesariamente, en conflicto con el sistema cooperativo que rige el modo de vida de nuestro campesino. Dentro de esta situación cabría que dicho indivíduo, que verá desaparecer la estructura social que durante muchos años le proporcionara el amparo de una forma económica patriarcal, para ser reemplazada por otra en donde solamente es válida su propia destreza y habilidad, sienta nostalgia de ella y se oponga, quizá violentamente, al cambio de valores que son necesarios para el proceso de industrialización. El sistema patriarcal del agro acostumbra al hombre a no tener responsabilidades, a actuar mecánicamente dentro de un complejo de normas que, aprisionándolo, le otorgan un sentimiento de seguridad por la eliminación de la lucha competitiva. Si repentinamente se sustituye dicho modo de vida por otro de tipo individualista, aparecerán frustraciones derivadas de la incapacidad de adaptación al nuevo sistema y se añorará el antíguo régimen que otrora fuera repudiado por el propio interesado.

Para iniciar un proceso de industrialización en el Perú es preciso, en cansecuencia, que se creen las condiciones sociales propicias a dicho desarrollo, a fin de eliminar, en la medida de lo posible, los factores que resultaren adversos a dicha transformación.

Es sabido que en el Perú no existe una cultura uniforme en sus distintas regiones, si bien es cierto que hay participación en valores comunes, como el sentimiento de patria, nación, etc. Ahora bien, la transformación de los patrones de cultura exige proyectos de planificación social que contemplen el problema en forma integral, es decir, en su diversidad social, sin limitarse únicamente al aspecto económico y de mano de obra disponible y adiestrada. Quizá la transformación social sea mucho más importante que la transformación económica propiamente tal, aún cuando la primera no puede darse sin la segunda. Un ejemplo de las consecuencias de la falta de previsión lo tenemos en la formación de los barrios miserables en las zonas aledañas a las grandes ciudades de la costa, como efecto de una industrialización incipiente de la zona urbana sin una consecuente reforma agraria. Las graves derivaciones de tal situación se han puesto de manifiesto en una serie de desajustes como delincuencia, prostitucián, desnutrición, deficiente salud mental, alto índice de mortalidad, insalubri- 
dad, situaciones conflictivas, etc., que son la constante preocupación del Estado y uno de sus más costosos problemas.

Una de las características de la ciencia es su poder de predicción. Gracias a él ha sido posible el dominio del mundo físico en el grado que se conoce. Algo semejante podría suceder en el campo social si se aplicaran los principios teóricos generales extraídos de los análisis científicos de la realidad actual. Las ciencias sociales están hoy día en capacidad de predecir la serie de consecuencias a derivarse de un proceso violento de transformación social. Es evidente que, en ese caso, sufrirán su impacto diversos sectores tanto sociales propiamente dichos como culturales y de la personalidad. La determinación anticipada de dichos efectos permite adoptar las medidas aconsejables para evitar la presencia de factores perturbadores de un normal y correcto desarrollo de la industria en el país.

La sociedad es un complejo de individuos y grupos que están actuando desde distintas posiciones, las cuaies les oiorgan diferentes deberes y derechos que se hacen efectivos a través de un comportamiento institucionalizado. Ahora bien, un rápido proceso de industrialización tiene que producir cambios en las instituciones, en las posiciones ocupadas por los grupos e individuos y en los derechos y deberes derivados de cada una de ellas. Sin duda algung î incrementorá la movilidad Ssocial vertical y aparecerá una nueva clase media a la que se lo exigirá alta callificación técnica. Si la industrialización no se acompaña con el fortalecimiento de las universidades podría darse el caso de tener que contar con una clase media sin preparación alguna, o quizá con la carencia de dicha clase, lo que irrogaría graves perjuicios al desarrollo económico total. Mientras, por una parte, la industria necesitará de ingenieros y técnicos, por otra, las universidades, con sus viejos moldes y pequeña capacidad no podrán proporcionárselos debido a que no se ha previsto el cambio de las instituciones paralelamente con el cambio de la actividad industrial. De igual manera, ningún tipo de desarrollo económico puede emprenderse en un país que cuenta con una tasa tan alta de analfabetismo como en el Perú. La falta de correspondencia entre instituciones, su desigual desarrollo, el mantenimiento de patrones culturales de tipo primitivo, etc., crearán estrangulamientos de tal magnitud que traería consigo problemas verdaderamente insolubles. 
De ahí que la programación de un desarrollo industrial debe estar acompañado neceriamente, con la programación del cambio social paralelo. Y es aquí donde desempeñan papel importante las Ciencias Sociales, en especial la Sociología. Estudios e investigaciones respecto de nuestra realidad social, de los factores favorables y adversos al cambio industrial, la determinación de las condiciones óptimas para la industrialización, del papel de los sindicatos, del liderazgo obrero, de las actitudes de los empresarios, etc., se hacen hoy necesarios como punto de partida para iniciar la planificación del desarrollo social que corresponda al desarrollo económico del país.

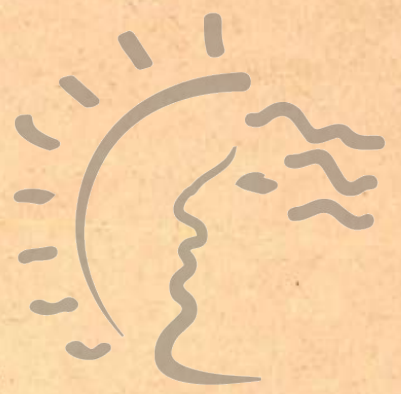

\section{Biblioteca de Letras "Jorge Puccinelli Converso"}

